Brazilian Journal

of Chemical

ISSN 0104-6632

Engineering

\title{
CORRELATION OF VAPOR - LIQUID EQUILIBRIUM DATA FOR ACETIC ACID - ISOPROPANOL - WATER - ISOPROPYL ACETATE MIXTURES
}

\author{
B. A. Mandagarán and E. A. Campanella* \\ Instituto de DesarrolloTecnológico para la Industria Química, \\ (Universidad Nacional del Litoral - CONICET), \\ Phone: (54) 342-4559174, 4559177, Fax: (54)342-4550944, \\ Güemes 3450 - S 3000 GLN Santa Fe - Argentina \\ E-mail: tquique@ceride.gov.ar
}

(Received: July 30, 2003 ; Accepted: August 03, 2005)

\begin{abstract}
A correlation procedure for the prediction of vapor - liquid equilibrium of acetic acid - isopropanol - water - isopropyl acetate mixtures has been developed. It is based on the NRTL model for predicting liquid activity coefficients, and on the Hayden-O'Connell second virial coefficients for predicting the vapor phase of systems containing association components. When compared with experimental data the correlation shows a good agreement for binary and ternary data. The correlation also shows good prediction for reactive quaternary data.

Keywords: Phase Equilibrium; Chemical Equilibrium; Reactive System; Esterification; Reactive Distillation.
\end{abstract}

\section{INTRODUCTION}

Reactive distillation has received increasing attention in the last decade. The combination of certain types of reactions and separation in a process unit brings important advantages such as overcoming azeotropes, increasing reaction yield, and reducing energy and capital costs. The most important among those reactions are reactions whose maximum conversion is limited by chemical equilibrium. The esterification reaction of isopropyl acetate is an example of such reactions.

Modeling of reactive distillation for a reliable process engineering design is quite complex, as it involves multicomponent vapor - liquid equilibria and chemical reaction. Thus, for achieving the process simulation required for design good correlation of the reactive vapor - liquid equilibrium of the quaternary acetic acid (1), isopropanol (2), water (3), isopropyl acetate (4) experimental data is necessary.

To correlate the vapor - liquid equilibrium in mixtures containing an associating component like acetic acid the Hayden-O'Connell (1975) second virial coefficients in combination with liquid activity coefficient models is usually applied. At present, there are at least four different types of correlation for the prediction of activity coefficients in chemical systems that are normally used: Wilson (1964), NRTL (Renon and Prausnitz, 1968), UNIQUAC (Abrams and Prausnitz, 1975) and UNIFAC (Fredenslund et al., 1975, 1977).

Lee and Kuo (1996) experimentally studied the vapor - liquid equilibrium behavior of the quaternary system acetic acid - isopropanol - water - isopropyl acetate at atmospheric pressure. To correlate their experimental data, they used UNIQUAC and Wilson with consideration of the association of acetic acid in

*To whom correspondence should be addressed 
the vapor phase using Hayden-O'Connell (1975) second virial coefficients. The optimization technique applied to determine the model parameters was similar to Kang et al. (1992) procedure and used the quaternary data.

Also, Teodorescu et al. (2001) studied the quaternary mixture and measured vapor - liquid equilibrium experimental points at $353.15 \mathrm{~K}$. They correlated their data by means of a maximum likelihood procedure by using the NRTL model. Binary model parameters for the four nonreacting binary subsystems were obtained from available experimental vapor - liquid equilibrium data by using either the Hayden-O'Connell (1975) or the Marek and Standart (1954) correction to account for the nonideality of the vapor phase. NRTL parameters for the water - isopropyl acetate and isopropanol acetic acid systems were estimated from a global optimization based on the quaternary data.

Song et al. (1997) measured residue curves in a series of simple distillation experiments. These curves allowed finding a four-component minimumboiling reactive azeotrope. Song et al. (1997) discovered a boiling state of constant composition and temperature in a mixture of acetic acid, isopropanol, water and isopropyl acetate that is simultaneously in both reaction and phase equilibrium, the reactive azeotrope.

In this study the NRTL model was used in combination with the Hayden-O'Connell (1975) second virial coefficient model for predicting the vapor - liquid equilibrium of the quaternary system containing acetic acid, isopropanol, water and isopropyl acetate. After choosing NRTL as the liquid phase model an analysis of the chemical equilibrium constant was done. Then, binary parameters were obtained from vapor - liquid equilibrium and azeotropic point data. Binary and ternary liquid liquid equilibria were used for the isopropyl acetate water binary parameters. The quaternary reactive azeotrope was correlated by fixing all the obtained binary parameters and using the NRTL model to obtain the chemical equilibrium constant that best fit the azeotrope. This correlation procedure is very different from those of Teodorescu et al. (2001) and Lee and Kuo (1996). Here the correlation predicts the quaternary reactive vapor - liquid equilibria. The calculated results are then compared with the two sets of quaternary experimental data available in the literature: Teodorescu et al. (2001) and Lee and Kuo (1996).

\section{VAPOR - LIQUID EQUILIBRIA WITH CHEMICAL EQUILIBRIUM}

The temperature, pressure, and composition of liquid and vapor in equilibrium are calculated by simultaneous solution of the equations describing phase and chemical equilibrium. For a vapor phase (superscript V) and a liquid phase (superscript L), at the same temperature and pressure, the equilibrium relationship for component $i$ is expressed in terms of fugacity $f_{i}$ :

$$
\mathrm{f}_{\mathrm{i}}^{\mathrm{V}}=\mathrm{f}_{\mathrm{i}}^{\mathrm{L}} \quad \mathrm{i}=1,2,3,4
$$

Using the fugacity coefficient, $\Phi_{\mathrm{i}}$, and the activity coefficient, $\gamma_{i}$, eq. 1 can be rewritten as :

$\Phi_{i} y_{i} P=\gamma_{i} x_{i} f_{i}^{0} \quad i=1,2,3,4$

where $\mathrm{f}_{\mathrm{i}}^{0}$ is the standard state fugacity.

The equilibrium constant for the esterification reaction in the liquid phase is defined by:

$$
\mathrm{K}={ }_{\mathrm{i}}\left(\mathrm{x}_{\mathrm{i}} \gamma_{\mathrm{i}}\right)^{v_{\mathrm{i}}} \quad \mathrm{i}=1,2,3,4
$$

with

$$
\mathrm{K}=\exp \left(-\mathrm{G}^{0} / \mathrm{RT}\right)
$$

where

$$
\Delta \mathrm{G}^{0}={ }_{\mathrm{i}} \mathrm{v}_{\mathrm{i}} \mathrm{Gi}^{0} \quad \mathrm{i}=1,2,3,4
$$

Ung and Doherty (1995) introduced a set of transformed composition variables $\left(\mathrm{X}_{\mathrm{i}}, \mathrm{Y}_{\mathrm{i}}\right)$, whose values remain constant during reaction and that sum to unity. For a single chemical reaction in a four component system, we can define three transformed compositions in each phase:

$$
\begin{aligned}
& X_{i}=\left(v_{k} x_{i}-v_{i} x_{k}\right) /\left(v_{k}-v_{T} x_{k}\right) \\
& i=1,2,3, \text { or } 4 \quad i k \\
& Y_{i}=\left(v_{k} y_{i}-v_{i} y_{k}\right) /\left(v_{k}-v_{T} y_{k}\right) \\
& i=1,2,3, \text { or } 4 \quad i k
\end{aligned}
$$

with

$$
v_{\tau}={ }_{i} v_{i}
$$


The subscript $\mathrm{k}$ represents a reference component, equivalent to isopropyl acetate in the case of this work. As seen from eqs. 6 and 7 transformed compositions could be negative or larger than one. However, they sum to unity. For the quaternary acetic acid (1), isopropanol (2), water (3), isopropyl acetate (4) system the transform composition variables taking isopropyl acetate as the reference component and using eq. 6 are:

$\mathrm{X}_{1}=\mathrm{x}_{1}+\mathrm{x}_{4}$

$\mathrm{X}_{2}=\mathrm{x}_{2}+\mathrm{x}_{4}$

$\mathrm{X}_{3}=\mathrm{x}_{3}-\mathrm{x}_{4}$

The same relations are obtained for the vapor phase using eq. 7. Two sums constrains for these new composition variable should be satisfied,

$$
\begin{aligned}
& X_{1}+X_{2}+X_{3}=1 \\
& Y_{1}+Y_{2}+Y_{3}=1
\end{aligned}
$$

By using the transformed composition variables the condition for a reactive azeotrope can be expressed as (Ung and Doherty, 1995),

$$
\mathrm{X}_{\mathrm{i}}=\mathrm{Y}_{\mathrm{i}}
$$

The fugacity coefficients and the standard state fugacities, and its necessary parameters and constants (vapor pressures, for example) that are needed to solve the phase and chemical equilibria equations were calculated with the virial equation of state and the Poynting correction using HYSYS (Hyprotech software) and DISTIL (AEA software). To calculate activity coefficients we used four different models: Wilson, NRTL, UNIQUAC and UNIFAC. For the esterification constant three values were considered: 10.7 calculated using eq. 5 with data from Yaws (1999), 8.7 experimental from Lee and Kuo (1996), 4.7 experimental from Teodorescu et al. (2001).

\section{RESULTS AND DISCUSSION}

Calculations done for correlating the quaternary reactive vapor-liquid equilibrium involved four steps: 1) choosing a liquid phase model, 2) analyzing chemical equilibrium constant effect, 3) binary parameter estimation, 4) chemical equilibrium constant determination. As already mentioned we did the calculation using DISTIL and HYSYS. The nonreactive azeotrope and phase equilibrium were calculated with DISTIL. The reactive azeotrope was calculated with HYSYS, the azeotrope was found optimizing a reactive separator tank by changing its feed. Reactive distillation lines and reactive bubble points were calculated using programs writing in the Macro Language Editor of HYSYS. In all the reactive phase equilibrium calculations, we used the transform coordinates of eqs. 6 and 7 to represent mixture compositions.

The first step to correlate the experimental data was choosing a model. We used the binary parameter information from HYSYS and DISTIL. As the isopropanol-isopropyl acetate binary parameters were not available in the database they were estimated using binary equilibrium data predicted with UNIFAC. In the case of the binary isopropyl acetate-water, also missing in the database, we used parameters estimated from binary (Sorensen and Arlt, 1979) and ternary (Hlavaty and Linek, 1973) liquid-liquid equilibria for UNIQUAC and NRTL, and from ternary (Linek and Wichterle, 1974) vaporliquid equilibria for Wilson. Table 1 presents calculation results using a value of 8.7 for the esterification equilibrium constant. The numbers of Table 1 allowed us to compare the performance of the most common activity coefficient models: UNIQUAC, Wilson, and NRTL. The Table shows a range for the experimental temperature and compositions when more than one experimental point is available. Also, in the Table are included prediction from UNIFAC. As seen in Table 1 the performances of UNIQUAC, Wilson and NRTL are similar when looking at the azeotropic temperature of nonreactive azeotropes and at the transformed molar fraction of the reactive azeotrope. We had chosen to correlate the quaternary data with NRTL.

The second step to correlate the reactive data was chemical equilibrium constant analysis. The effect of the constant was evaluated together with the effect of the isopropanol - isopropyl acetate and isopropanol water binary parameters. We did a two-level analysis to see how important the factor (chemical equilibrium constant or binary parameter) was on calculations. We have used two levels ( + and -$)$ of binary vapor-liquid equilibrium data and chemical equilibrium constant to evaluate the influence of data on the model representation of the quaternary reactive mixture. For the binary isopropanol isopropyl acetate we chose two azeotropic points from Gmehling et al. (1994): $80.1{ }^{\circ} \mathrm{C}, \quad 0.6507$ (isopropanol) as the + level and $81.1^{\circ} \mathrm{C}, 0.6926$ (isopropanol) as the - level. For the binary isopropanol - water we chose two set of data from Wilson and Simons (1952): the + level at $\mathrm{P}=0.125$ atm and the - level at $\mathrm{P}=4.06 \mathrm{~atm}$. For the chemical equilibrium constant we chose 10.9 as the + level and 4.7 as the - level. We did calculations that combined the three factors at two-level factorial design (Miller and Miller, 1993). Table 2 summarizes the results of the two-level analysis calculation; each number in the Table is the average of four results. The way that factors are changed in 
the two-level factorial design implies that we have actually performed four little one factor at a time change and obtained four separated estimates of factor effect, each for a combination of setting of the other two factors. The effects are presented as deviations in temperature and in molar fraction for the azeotropes and as deviation in the mean absolute deviation for the vapor - liquid equilibrium data. The
Table shows that the influence of the uncertainty in value of the esterification equilibrium constant is very important for representing the phase and chemical behavior of the quaternary mixture. Due to the experimental dispersion of the esterification constant and to its importance, we chose to adjust the chemical equilibrium constant using the experimental reactive azeotrope.

Table 1: Experimental ${ }^{a}$ and calculated azeotropes for acetic acid (1), isopropanol (2),water (3), isopropyl acetate (4).

\begin{tabular}{|l|c|c|r|r|r|}
\hline \multicolumn{1}{|c|}{ System $^{\mathbf{b}}$} & UNIQUAC & Wilson & NRTL & UNIFAC & Experimental \\
\hline $\mathrm{T}(2-3-4),{ }^{\circ} \mathrm{C}$ & 74.83 & 74.12 & 74.69 & - & 75.50 \\
$\mathrm{X}_{2}$ & 0.2469 & 0.2233 & 0.2440 & - & 0.1377 \\
$\mathrm{X}_{3}$ & 0.3616 & 0.3319 & 0.3600 & - & 0.3886 \\
$\mathrm{~T}(3-4),{ }^{\circ} \mathrm{C}$ & 77.39 & 75.16 & 77.19 & 77.48 & $75.90-76.60$ \\
$\mathrm{X}_{3}$ & 0.4159 & 0.3816 & 0.4120 & 0.4183 & $0.4144-0.3592$ \\
$\mathrm{~T}(2-3),{ }^{\circ} \mathrm{C}$ & 79.97 & 79.69 & 80.01 & 80.09 & $79.70-80.72$ \\
$\mathrm{X}_{2}$ & 0.6757 & 0.6952 & 0.6707 & 0.6864 & $0.6645-0.7041$ \\
$\mathrm{~T}(2-4),{ }^{\circ} \mathrm{C}$ & 78.95 & 79.01 & 0.6285 & 79.28 & $80.10-81.00$ \\
$\mathrm{X}_{2}$ & 0.6331 & 0.6368 & 78.13 & 0.6403 & $0.6507-0.6926$ \\
$\mathrm{~T}(1-2-3-4),{ }^{\circ} \mathrm{C}$ & 78.11 & 77.63 & 0.2976 & 0.2534 & 78.60 \\
$\mathrm{X}_{1}$ & 0.2923 & 0.2998 & 0.7995 & 0.7379 & 0.2680 \\
$\mathrm{X}_{2}$ & 0.7806 & 0.7781 & & 0.7790 \\
\hline
\end{tabular}

a. Non reactive azeotropes: Gmehling et al.(1994). Reactive azeotrope: Song et al.(1997).

b. T(2-3-4) is temperature for the isopropanol-water-isopropyl acetate ternary azeotrope. $\mathrm{X}$ is transformed molar fraction (eq. 6).

Table 2: Summary of NRTL calculations for acetic acid (1), isopropanol (2), water (3), isopropyl acetate (4) changing esterification equilibrium constant and binaryparameters.

\begin{tabular}{|c|c|c|c|c|}
\hline \multirow{2}{*}{$\begin{array}{l}\text { Azeotrope / } \\
\text { System }\end{array}$} & \multirow[b]{2}{*}{ Variable } & \multicolumn{3}{|c|}{ Variation Effect $^{\text {a }}$} \\
\hline & & $\begin{array}{c}\text { Esterification } \\
\text { constant (K) }\end{array}$ & $\begin{array}{c}\text { Binary param. } \\
2-4 \text { (B1) }\end{array}$ & $\begin{array}{c}\text { Binary param. } \\
2-3 \text { (B2) }\end{array}$ \\
\hline $2-3-4$ & $\begin{array}{c}\mathrm{T},{ }^{\circ} \mathrm{C} \\
\mathrm{x}_{1} \\
\mathrm{x}_{2}\end{array}$ & $\begin{array}{l}- \\
- \\
-\end{array}$ & $\begin{array}{r}-0.5200 \\
0.0235 \\
-0.0104 \\
\end{array}$ & $\begin{array}{r}0.2000 \\
0.0095 \\
-0.0094 \\
\end{array}$ \\
\hline $2-3$ & $\begin{array}{c}\mathrm{T},{ }^{\circ} \mathrm{C} \\
\mathrm{x}_{1}\end{array}$ & $\begin{array}{l}- \\
-\end{array}$ & $\begin{array}{l}- \\
- \\
\end{array}$ & $\begin{array}{r}-0.6300 \\
0.0005 \\
\end{array}$ \\
\hline $2-4$ & $\begin{array}{c}\mathrm{T},{ }^{\circ} \mathrm{C} \\
\mathrm{x}_{1}\end{array}$ & - & $\begin{array}{l}-0.9000 \\
-0.0419 \\
\end{array}$ & $\begin{array}{l}- \\
-\end{array}$ \\
\hline $1-2-3-4$ & $\begin{array}{c}\mathrm{T},{ }^{\circ} \mathrm{C} \\
\mathrm{X}_{1} \\
\mathrm{X}_{2} \\
\end{array}$ & $\begin{array}{r}-1.0650 \\
0.0880 \\
-0.0424 \\
\end{array}$ & $\begin{array}{r}-0.5300 \\
0.0723 \\
0.0484 \\
\end{array}$ & $\begin{array}{l}-0.2700 \\
-0.0413 \\
-0.0221 \\
\end{array}$ \\
\hline $1-2-3-4^{b}$ & $\begin{array}{c}\mathrm{T},{ }^{\circ} \mathrm{C} \\
\mathrm{x}_{1} \\
\mathrm{y}_{1} \\
\mathrm{y}_{2} \\
\mathrm{y}_{3} \\
\end{array}$ & $\begin{array}{r}0.7650 \\
-0.0002 \\
0.0001 \\
-0.0055 \\
0.0066 \\
\end{array}$ & $\begin{array}{r}0.0750 \\
0.0024 \\
0.0001 \\
0.0004 \\
-0.0039 \\
\end{array}$ & $\begin{array}{r}-0.0100 \\
-0.0009 \\
0.0003 \\
0.0004 \\
0.0018 \\
\end{array}$ \\
\hline $1-2-3-4^{c}$ & $\begin{array}{c}\mathrm{T},{ }^{\circ} \mathrm{C} \\
\mathrm{x}_{1} \\
\mathrm{y}_{1} \\
\mathrm{y}_{2} \\
\mathrm{y}_{3}\end{array}$ & $\begin{array}{l}-2.7150 \\
-0.0565 \\
-0.0515 \\
-0.0028 \\
-0.0036\end{array}$ & $\begin{array}{r}0.0450 \\
0.0013 \\
0.0008 \\
0.0007 \\
-0.0012\end{array}$ & $\begin{array}{r}0.1550 \\
0.0004 \\
-0.0003 \\
0.0020 \\
0.0036\end{array}$ \\
\hline
\end{tabular}

a. As deviation

b. Experimental data from Teodorescu et al. ( 2001)

c. Experimental data from Lee and Kuo ( 1996) 
A third step to correlate the experimental data was binary parameter determination. For the binary isopropanol (1) - isopropyl acetate (2) we had estimated the binary parameters from an azeotropic point datum $\left(\mathrm{T}=80.1{ }^{\circ} \mathrm{C} ; \mathrm{x}_{1}=0.6507\right)$. For the binary isopropyl acetate - water we had estimated parameters from binary (Sorensen and Arlt, 1979) and ternary (Hlavaty and Linek, 1973) liquid - liquid equilibria. For the other four binary systems, we used the binary data of Table 3 . Table 4 lists the obtained NRTL binary parameters. The Table also shows vapor pressure information and virial association parameters for the isopropyl acetate system. Figures 1-4 show that the model can correlate well vapor - liquid equilibrium of the four binary systems, including predicting very well the azeotropic behavior of the isopropanol - water system. Table 3 shows the mean deviation between measured and calculated values for the systems of Figures 1-4 compared against the mean deviation of the Gmehling et al. (1977-1979). It can be seen that the set of
Gmehling et al. (1977-1979) shows larger deviations. Figure 5 shows liquid - liquid equilibrium calculations for the water - isopropyl acetate - acetic acid system compared against experimental values. It can be seen that NRTL can correlate the liquid-liquid behavior of the mixture. From Figure 6 that shows vapor - liquid prediction for the water - isopropyl acetate - acetic acid system, it can be seen that the same set of binary parameters used in the liquid - liquid equilibrium predict quite well vapor - liquid equilibrium. Figure 7 shows vapor - liquid prediction for the isopropyl acetate - isopropanol system. Table 5 displays experimental and calculated azeotropic point comparison. It could appreciate that predictions are very good because binary parameters were obtained using azeotropic point at different conditions. Figure 8 shows vapor - liquid - liquid equilibrium for the isopropyl acetate - isopropanol - water system. In spite that in this case the test for model and parameters is more severe, prediction is fair.

Table 3: Mean deviation between measured and predicted temperature and vapor compositions a .

\begin{tabular}{|c|c|c|c|c|c|}
\hline \multirow{2}{*}{ System } & \multirow{2}{*}{ Data reference } & \multicolumn{2}{|c|}{ Gmehling et al. (1977-1979) } & \multicolumn{2}{|c|}{ This work } \\
\hline & & $\Delta \mathbf{T}$ & $\Delta \mathbf{y}_{1}$ & $\Delta \mathbf{T}$ & $\Delta \mathrm{y}_{1}$ \\
\hline $\begin{array}{l}\text { Acetic acid (1) } \\
\text { Water (2) }\end{array}$ & $\begin{array}{l}\text { Sebastiani and Lacquaniti } \\
\text { (1967) }\end{array}$ & $0.83(1.13)$ & $0.0195(0.0453)$ & $0.18(0.48)$ & $0.0192(0.0476)$ \\
\hline $\begin{array}{l}\text { Acetic acid (1) } \\
\text { Isopropanol (2) }\end{array}$ & $\begin{array}{l}\text { Amer Amezaga and Fernandez } \\
\text { Biarge (1983) }\end{array}$ & $2.53(4.54)$ & $0.0409(0.0843)$ & $1.12(2.06)$ & $0.0366(0.0869)$ \\
\hline $\begin{array}{l}\text { Acetic acid (1) } \\
\text { Isopropyl acetate(2) }\end{array}$ & Linek and Wichterle (1974) & $0.63(1.23)$ & $0.0142(0.0247)$ & $0.40(0.57)$ & $0.0275(0.0514)$ \\
\hline $\begin{array}{l}\text { Isopropanol (1) } \\
\text { Water (2) }\end{array}$ & Wilson and Simons (1952) & $1.11(2.31)$ & $0.0140(0.0239)$ & $0.19(0.59)$ & $0.0053(0.0219)$ \\
\hline
\end{tabular}

a. $\Delta \mathrm{T}, \Delta \mathrm{y}_{1}=\left(\sum_{\mathrm{i}} \mid\right.$ measured value - calculated value $\left.\mid\right) / \mathrm{k}$

$\mathrm{i}=1 \ldots \mathrm{k}, \mathrm{k}=$ total number of data points. In parenthesis maximum absolute deviation.

Table 4: Thermodynamic data for the system acetic acid + isopropanol + water +isopropyl acetate.

\begin{tabular}{|c|c|c|c|c|}
\hline Component $^{\mathrm{a}}$ & Acetic acid & Isopropanol & Water & Isopropyl acetate \\
\hline $\begin{array}{l}\text { Normal boiling point, }{ }^{\circ} \mathrm{C} \\
\text { Vapor pressure coefficient } \\
\text { A } \\
\text { B } \\
\text { C } \\
\text { D } \\
\text { E } \\
F \\
\text { NRTL parameter } \mathbf{a}_{\mathrm{ij}} \\
\mathrm{j}=\text { Acetic acid } \\
\mathrm{j}=\text { Isopropanol } \\
\mathrm{j}=\text { Water } \\
\mathrm{j}=\text { Isopropyl acetate } \\
\text { NRTL parameter } \boldsymbol{\alpha}_{\mathrm{ij}} \\
\mathrm{j}=\text { Acetic acid } \\
\mathrm{j}=\text { Isopropanol } \\
\mathrm{j}=\text { Water } \\
\mathrm{j}=\text { Isopropyl acetate } \\
\text { Virial association parameter } \eta_{\mathrm{ij}} \\
\mathrm{j}=\text { Acetic acid } \\
\mathrm{j}=\text { Isopropanol } \\
\mathrm{j}=\text { Water } \\
\mathrm{j}=\text { Isopropyl acetate }\end{array}$ & $\begin{array}{c}117.95 \\
61.34090 \\
-6768.88 \\
0 \\
-6.72663 \\
4.84 \mathrm{E}-6 \\
2 \\
\mathbf{i}=\text { Acetic acid } \\
0.0000 \\
-294.6577 \\
-204.0719 \\
-426.2730 \\
\mathbf{i}=\text { Acetic acid } \\
0.0000 \\
0.3048 \\
0.2997 \\
0.3014 \\
\mathbf{i}=\text { Acetic } \text { acid } \\
4.5000 \\
2.5000 \\
2.5000 \\
0.0000\end{array}$ & $\begin{array}{c}82.25 \\
83.63700 \\
-8249.01 \\
0 \\
-9.54518 \\
2.00272 \mathrm{E}-06 \\
2 \\
\mathbf{i}=\text { Isopropanol } \\
-115.9064 \\
0.0000 \\
184.8203 \\
188.6209 \\
\mathbf{i}=\mathbf{I s o p r o p a n o l} \\
0.3048 \\
0.0000 \\
0.4520 \\
0.3000 \\
\mathbf{i}=\text { Isopropanol } \\
2.5000 \\
1.3200 \\
1.5500 \\
0.0000\end{array}$ & $\begin{array}{c}100.00 \\
65.92780 \\
-7227.53 \\
0 \\
-7.17695 \\
4.03 \text { E-6 } \\
2 \\
\mathbf{i}=\text { Water } \\
900.3907 \\
1834.9791 \\
0.0000 \\
2727.2256 \\
\mathbf{i}=\text { Water } \\
0.2997 \\
0.4520 \\
0.0000 \\
0.3135 \\
\mathbf{i}=\text { Water } \\
2.5000 \\
1.5500 \\
1.7000 \\
0.0000\end{array}$ & $\begin{array}{c}49.11600 \\
-5753.89 \\
0 \\
-4.89750 \\
1.61000 \mathrm{E}-06 \\
2 \\
\text { i=Isopropyl acetate } \\
1136.3250 \\
379.1688 \\
936.5338 \\
0.0000 \\
\text { i=Isopropyl acetate } \\
0.3014 \\
0.3000 \\
0.3135 \\
0.0000 \\
\text { i=Isopropyl acetate } \\
0.0000 \\
0.0000 \\
0.0000 \\
0.0000\end{array}$ \\
\hline
\end{tabular}

a. $\ln P_{\text {vap }}=A+B /(C+T)+D * \ln T+E^{*} T^{F}, T(K), P_{v a p}(k P a) \ln { }_{i}=\left(\sum_{j j i} x_{j} G_{j i}\right) /\left(\sum_{k} x_{k} G_{k i}\right)+\sum_{j}\left(x_{j} G_{i j} / x_{k} G_{k j}\right)\left[\quad j_{j j}-\left(\sum_{m} \quad m i\right.\right.$ $\left.\mathrm{x}_{\mathrm{k}} \mathrm{G}_{\mathrm{kj}}\right]$ with $\mathrm{i}, \mathrm{j}, \mathrm{k}, \mathrm{m}=1, \ldots, \mathrm{n} ; \mathrm{G}_{\mathrm{ij}}=\exp [-\mathrm{ij}$ ij $] ; \mathrm{ij}^{\mathrm{ij}}=\mathrm{a}_{\mathrm{ij}} / \mathrm{RT}$ 


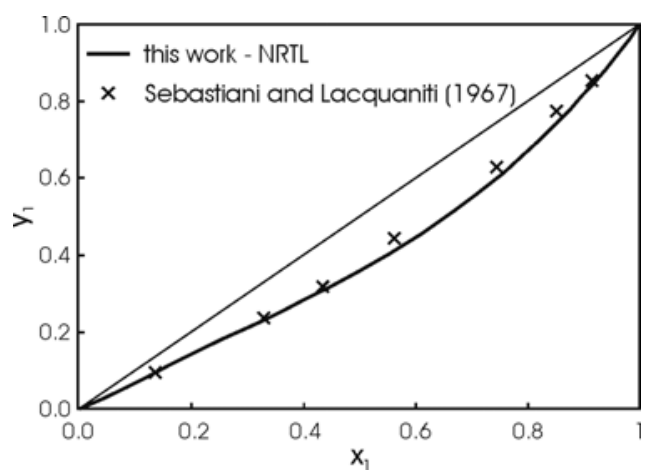

Figure 1: Experimental and calculated mixture behavior of the binary system acetic acid (1) - water (2) at $\mathrm{P}=1 \mathrm{~atm}$.

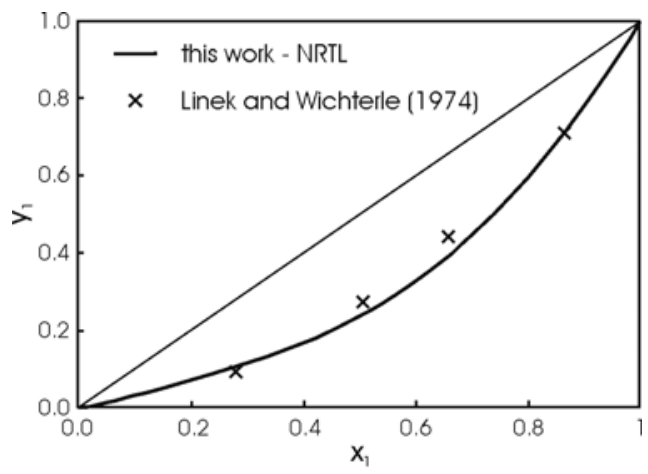

Figure 3: Experimental and calculated mixture behavior of the binary system acetic acid (1) - isopropyl acetate (2) at $\mathrm{P}=0.2632 \mathrm{~atm}$.

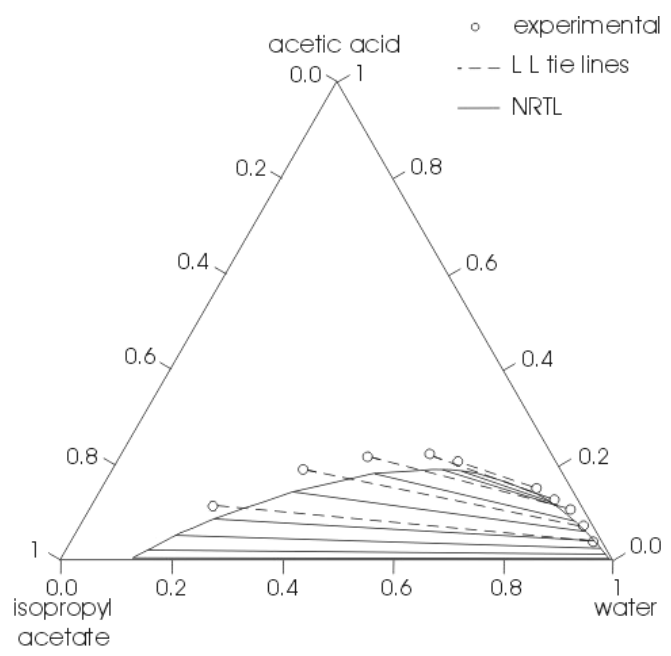

Figure 5: Experimental and calculated ternary liquid-liquid equilibria at $\mathrm{P}=1 \mathrm{~atm}$ and $\mathrm{T}=24.60{ }^{\circ} \mathrm{C}$. Experimental data from Hlavaty and Linek (1973).

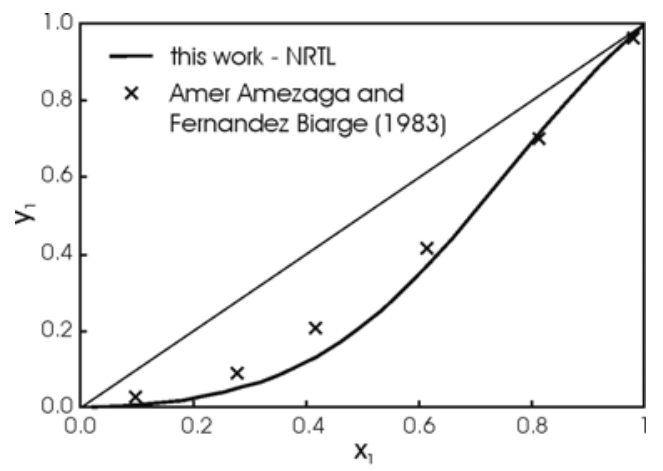

Figure 2: Experimental and calculated mixture behavior of the binary system acetic acid

(1) - isopropanol (2) at $\mathrm{P}=1 \mathrm{~atm}$.

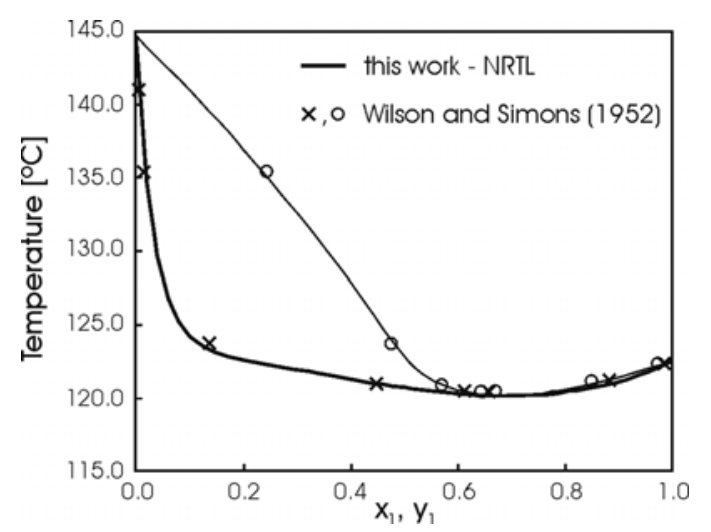

Figure 4: Experimental and calculated mixture behavior of the binary system isopropanol (1) - water (2) at $\mathrm{P}=4.062 \mathrm{~atm}$.

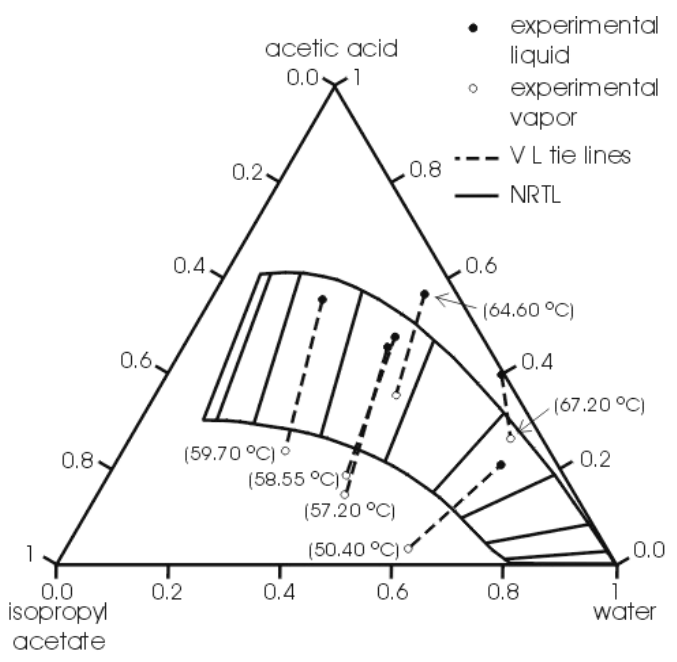

Figure 6: Experimental and calculated ternary vapor-liquid equilibria. Calculated points at $\mathrm{P}=$ $0.2632 \mathrm{~atm}$ and $\mathrm{T}=61.89^{\circ} \mathrm{C}$. Experimental data from Linek and Wichterle (1974). Experimental temperature in parenthesis. 


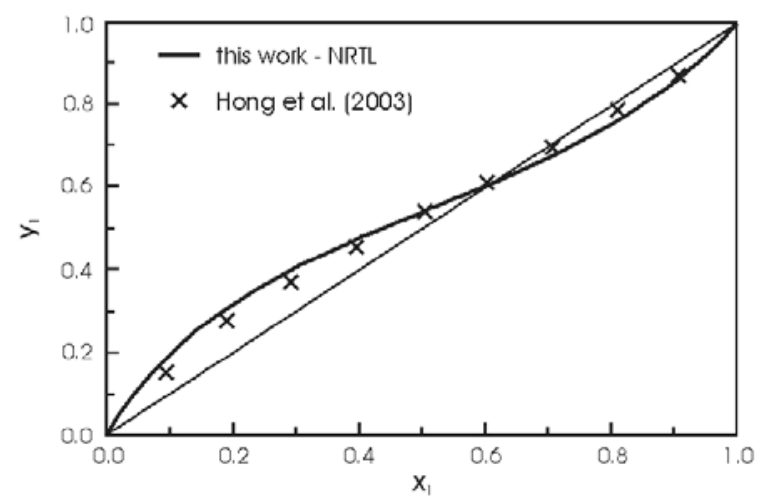

Figure 7: Experimental and predicted mixture behavior of the binary system isopropanol (1) - isopropyl acetate (2) at $80^{\circ} \mathrm{C}$.

Table 5: Experimental and calculated azeotropic points for isopropyl acetate(1), isopropanol (2).

\begin{tabular}{|c|c|c|c|c|}
\hline P, atm & \multicolumn{2}{|c|}{ T, $^{\mathbf{}} \mathbf{C}$} & \multicolumn{2}{c|}{$\mathbf{x}_{\mathbf{1}}$} \\
\hline & Exp. $^{\text {a }}$ & Calc. & Exp. $^{\text {a }}$ & 0.4582 \\
0.4569 & 60.00 & 60.47 & 0.492 & 0.3506 \\
0.9909 & 80.00 & 79.86 & 0.321 & 0.2501 \\
1.9960 & 100.00 & 99.56 & 0.203 & 0.2501 \\
\hline
\end{tabular}

Experimental data from Hong et al. (2003).

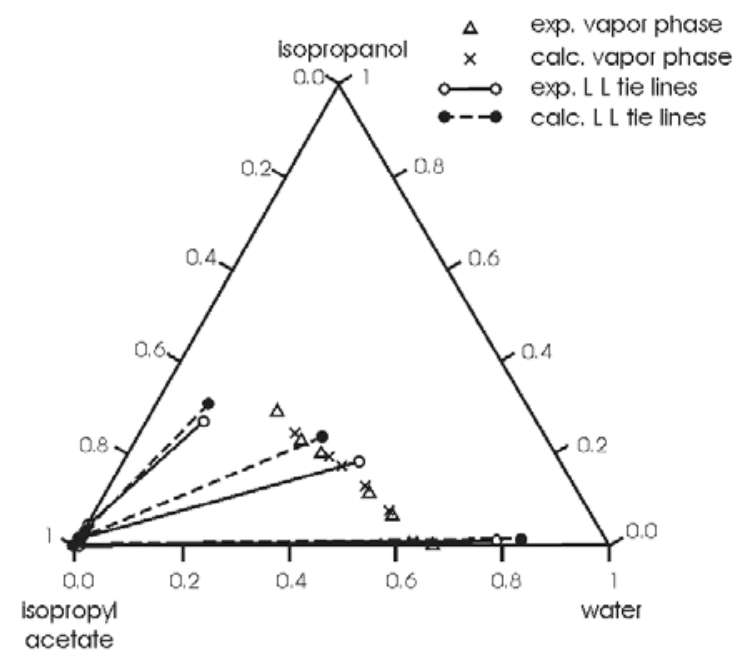

Figure 8: Experimental and predicted vapor-liquid-liquid equilibria for isopropanol (1) - water (2) - isopropyl acetate (3) at $45^{\circ} \mathrm{C}$. Experimental data from Hong et al. (2003).

The final step to correlate the quaternary vapor liquid equilibrium data was chemical equilibrium constant adjustment against the reactive azeotrope. A value of 10.7 was finally chosen. Table 6 shows the calculated nonreactive and reactive azeotropes using the binary parameters of Table 4 and a chemical equilibrium constant of 10.7. From the table, it can be seen that NRTL can well correlate the reactive azeotrope and can predict very well all nonreactive azeotropes. Maier et al. (2000) did calculation using NRTL and taking a chemical equilibrium constant of 8.7. Their calculated reactive azeotrope shows a larger error than the calculated in this work. This result is not surprising because in this work calculated reactive azeotrope is adjusted to the experimental one. Vapor and liquid molar fraction are different at the reactive quaternary azeotrope. The liquid and vapor transformed molar fraction 
must be equal at azeotropic conditions as established by eq. 14 . However, when calculations are done with the molar fractions of Table 6 small difference between the vapor and the liquid transformed molar fraction show up : $\mathrm{X}_{1}=0.2680, \mathrm{Y}_{1}=0.2700, \mathrm{X}_{2}=$ $0.7790, Y_{2}=0.7610$ for the experimental azeotropic point, and $\mathrm{X}_{1}=0.2783, \mathrm{Y}_{1}=0.2798, \mathrm{X}_{2}=0.7817, \mathrm{Y}_{2}$ $=0.7827$ for the calculated azeotropic point. The small differences for the calculated transformed compositions are due to the way reactive azeotrope are calculated with HYSYS. The feed to a reactive three phase flash is changed until the azeotropic point is found. Reactive azeotropic location is also calculated using distillation lines like those of Figure 9. Besides, the three phase flash allows finding if the reactive azeotrope is heterogeneous as in the n-butyl acetate system (Campanella and Mandagarán, 2003). In this case, the calculated as well the experimental reactive azeotrope are homogeneous. In summary, the model used to describe the reactive vapor - liquid system is predictive. The correlating procedure used in this work to obtain the binary parameters and the chemical equilibrium constant is different from those procedures of Teodorescu et al. (2001) and Lee and Kuo (1996). Results for the quaternary reactive system are presented in Table 7, 8 and in Figure 9.

Table 6: Calculated azeotropes for acetic acid(1), isopropanol(2), water(3), isopropyl acetate(4) with NRTL using thermodynamic data of Table 4 and $K=10.7$.

\begin{tabular}{|c|c|c|c|c|c|}
\hline $\begin{array}{c}\text { System / } \\
\text { Azeotrope }\end{array}$ & $\mathbf{2 - 3 - 4}$ & $\mathbf{3 - 4}$ & $\mathbf{1 - 2 - 3 - 4} \mathbf{~}^{\mathbf{a}}$ & $\mathbf{2 - 3}$ & $\mathbf{2 - 4}$ \\
\hline $\mathrm{T},{ }^{\circ} \mathrm{C}$ & $\mathbf{7 5 . 2 4}$ & $\mathbf{7 7 . 1 9}$ & $\mathbf{7 9 . 1 3 ( 7 8 . 6 0 )}$ & 80.53 & - \\
$\mathrm{x}_{1}$ & - & - & $0.0574(0.0540)$ & - & - \\
$\mathrm{y}_{1}$ & - & - & $0.0031(0.0000)$ & 0.6855 & 0.6507 \\
$\mathrm{x}_{2}$ & 0.2088 & - & $0.5608(0.5650)$ & 0.6855 & 0.6507 \\
$\mathrm{y}_{2}$ & 0.2088 & - & $0.5060(0.4910)$ & 0.3145 & - \\
$\mathrm{x}_{3}$ & 0.3751 & 0.4120 & $0.1608(0.1670)$ & 0.3145 & - \\
$\mathrm{y}_{3}$ & 0.3751 & 0.4120 & $0.2141(0.2390)$ & - & 0.3493 \\
$\mathrm{x}_{4}$ & 0.4161 & 0.5880 & $0.2209(0.2140)$ & - & 0.3493 \\
$\mathrm{y}_{4}$ & 0.4161 & 0.5880 & $0.2767(0.2700)$ & & \\
\hline
\end{tabular}

a. In parenthesis experimental data (Song et al., 1997).

Table 7: Statistical Errors for ASOG, Wilson, UNIQUAC and NRTL Models.

\begin{tabular}{|c|c|c|c|c|c|c|}
\hline Error $^{a}$ & $\begin{array}{c}\text { ASOG } \\
\text { Tochigi et al. } \\
\text { (1977) } \\
\end{array}$ & $\begin{array}{c}\text { Wilson } \\
\text { Lee and Kuo } \\
(1996)\end{array}$ & $\begin{array}{c}\text { UNIQUAC } \\
\text { Lee and Kuo } \\
(1996)\end{array}$ & $\begin{array}{c}\text { NRTL } \\
\text { Teodorescu et } \\
\text { al. (2001) } \\
\end{array}$ & NRTL-T ${ }^{b}$ & NRTL-K $^{\mathbf{b}}$ \\
\hline $\begin{array}{l}\text { RMSD } \\
\mathrm{T},{ }^{\circ} \mathrm{C} \\
\mathrm{x}_{1} \\
\mathrm{x}_{2} \\
\mathrm{x}_{3} \\
\mathrm{y}_{1} \\
\mathrm{y}_{2} \\
\mathrm{y}_{3} \\
\mathrm{MD} \\
\mathrm{T},{ }^{\circ} \mathrm{C} \\
\mathrm{x}_{1} \\
\mathrm{x}_{2} \\
\mathrm{x}_{3} \\
\mathrm{y}_{1} \\
\mathrm{y}_{2} \\
\mathrm{y}_{3} \\
\end{array}$ & $\begin{array}{c}- \\
- \\
- \\
- \\
- \\
- \\
- \\
\\
1.52 \\
- \\
- \\
- \\
0.0120 \\
0.0260 \\
0.0280\end{array}$ & $\begin{array}{c}2.00 \\
- \\
- \\
- \\
0.0570 \\
0.0110 \\
0.0380 \\
1.90 \\
- \\
- \\
- \\
0.0500 \\
0.0070 \\
0.0330\end{array}$ & $\begin{array}{c}1.00 \\
- \\
- \\
- \\
0.0600 \\
0.0120 \\
0.0230 \\
1.00 \\
- \\
- \\
- \\
0.0520 \\
0.0100 \\
0.0200\end{array}$ & $\begin{array}{c}- \\
- \\
- \\
- \\
- \\
- \\
- \\
0.07 \\
0.0181 \\
0.0080 \\
0.0074 \\
0.0192 \\
0.0227 \\
0.0201\end{array}$ & $\begin{array}{r}1.52 \\
0.0524 \\
0.0000 \\
0.0000 \\
0.0498 \\
0.0167 \\
0.0360 \\
\\
1.27 \\
0.0433 \\
0.0000 \\
0.0000 \\
0.0266 \\
0.0141 \\
0.0311 \\
\end{array}$ & $\begin{array}{r}0.72 \\
0.0170 \\
0.0000 \\
0.0000 \\
0.0092 \\
0.0073 \\
0.0143 \\
\\
0.63 \\
0.0142 \\
0.0000 \\
0.0000 \\
0.0069 \\
0.0068 \\
0.0123 \\
\end{array}$ \\
\hline
\end{tabular}

a. $\mathrm{RMSD}=$ root mean square deviation; $\mathrm{MD}=$ mean deviation

$\left.\mathrm{RMSD}=\left(\mathrm{i}\left(\mathrm{Z}_{\mathrm{i}}\right)^{2}\right) / \mathrm{n}\right)^{1 / 2}, \mathrm{MD}=\left(\mathrm{i}_{\mathrm{i}} \mathrm{Z}_{\mathrm{i}}\right) / \mathrm{n}, \mathrm{Z}=$ measured value - calculated value

$\mathrm{n}=$ total number of data points.

b. NRTL-T this work (Teodorescu et al. (2001) data); NRTL-K this work (Lee and Kuo (1996) data). 
Table 8: Calculated and measured reactive azeotropes

\begin{tabular}{|l|c|c|c|c|}
\hline & $\begin{array}{c}\text { This work } \\
(\mathbf{K}=\mathbf{1 0 . 7})\end{array}$ & $\begin{array}{c}\text { Song et al. (calculated } \\
\text { with K= 8.7) }\end{array}$ & $\begin{array}{c}\text { Song et al. } \\
\text { (experimental) }\end{array}$ & $\begin{array}{c}\text { Maier et al. } \\
\text { (K= 8.7) }\end{array}$ \\
\hline $\mathrm{T}^{\circ}{ }^{\circ} \mathrm{C}$ & 79.13 & 78.99 & 78.60 & 79.70 \\
$\mathrm{x}_{1}$ & 0.0574 & 0.0530 & 0.0540 & 0.0480 \\
$\mathrm{x}_{2}$ & 0.5608 & 0.5655 & 0.5650 & 0.5650 \\
$\mathrm{x}_{3}$ & 0.1608 & 0.1628 & 0.1670 & 0.1830 \\
$\mathrm{x}_{4}$ & 0.2209 & 0.2187 & 0.2140 & 0.2040 \\
$\mathrm{y}_{1}$ & 0.0031 & 0.0033 & 0.0000 & 0.0030 \\
$\mathrm{y}_{2}$ & 0.5060 & 0.5158 & 0.4910 & 0.5200 \\
$\mathrm{y}_{3}$ & 0.2141 & 0.2125 & 0.2390 & 0.2280 \\
$\mathrm{y}_{4}$ & 0.2767 & 0.2684 & 0.2700 & 0.2490 \\
$\mathrm{X}_{1}$ & 0.2783 & 0.2717 & 0.2680 & 0.2310 \\
$\mathrm{X}_{2} \mathrm{xx}^{\mathrm{a}}$ & 0.7817 & 0.7842 & 0.7790 & 0.7480 \\
$\Delta \mathrm{y}^{\mathrm{a}}$ & 0.0107 & 0.0064 & - & 0.0198 \\
$\Delta \mathrm{T}^{\mathrm{b}},{ }^{\mathrm{o}} \mathrm{C}$ & 0.0300 & 0.0365 & - & 0.0376 \\
\end{tabular}

a. $\Delta \mathrm{x}, \Delta \mathrm{y}=\left(\sum_{\mathrm{i}}\left(\Delta \mathrm{Z}_{\mathrm{i}}\right)^{2}\right)^{1 / 2}, \Delta \mathrm{Z}=$ measured value - calculated value

b. $\Delta \mathrm{T}=$ measured value - calculated value

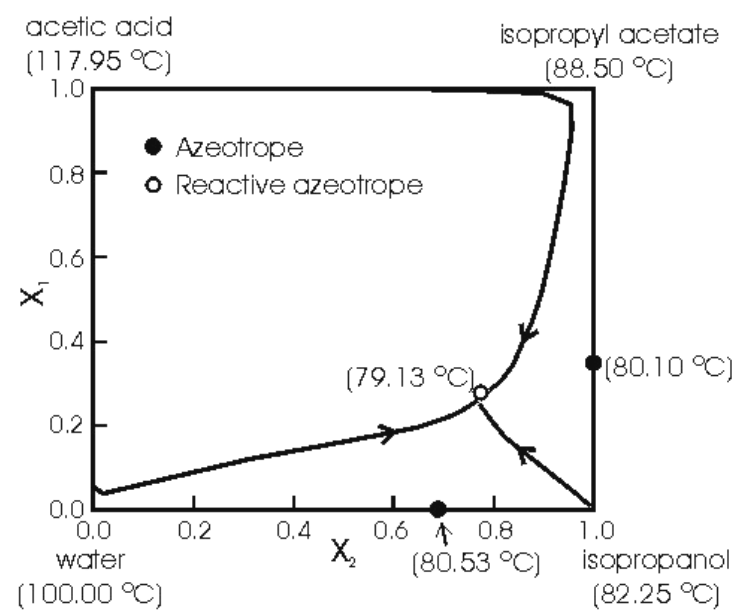

Figure 9: Calculated distillation line diagram for acetic acid (1) - isopropanol

(2) - water (3) -isopropyl acetate (4) mixtures at $\mathrm{P}=1 \mathrm{~atm}$.

Table 7 shows the mean deviation (MD) and the root mean square deviation (RMSD) between the measured and the predicted quaternary vapor - liquid equilibrium. Under the heading of NRTL-K the numbers are the difference between calculated values and Lee and Kuo (1996) experimental values. Under the heading of NRTL-T the numbers are the difference between calculated values and Teodorescu et al. (2001) experimental values. Correlation using ASOG is also presented under the heading of ASOG as reported from Tochigi et al. (1977). Lee and Kuo (1996) correlation of theirs data are presented under the heading of Wilson using Wilson equation and under the heading of UNIQUAC using UNIQUAC model. Teodorescu et al. (2001) correlation of theirs data is presented in the column label as NRTL. To evaluate the performance of the model we did bubble point calculation. We fixed pressure, isopropanol and water liquid molar fraction as required by the phase rule for a reacting system with only one chemical reaction. For this reason, errors in those variables are zero in the numbers reported under columns NRTL$\mathrm{K}$ and NRTL-T. Errors in temperature and in vapor molar fractions are lower than errors reported by Lee and Kuo (1996) and Tochigi et al. (1977). Errors in vapor molar fractions are lower than errors reported by Teodorescu et al. (2001). It is important to note that we used only one value for the chemical equilibrium constant for the two sets of data. This value of the constant (10.7) was different from the 
value used by Lee and Kuo (8.7) and the value used by Teodorescu et al. (4.7). Lee and Kuo (1996) did not report azeotropic point. Teodorescu et al. (2001) reported using a graph a possible location of the reactive azeotrope; but they did not compare its location with the experimental datum of Song et al. (1997).

Table 8 shows calculated and measured reactive azeotropes. All reactive azeotropes were calculated using NRTL equation. They differ in the values of the binary parameters and in the value of the chemical equilibrium constant. The calculated reactive azeotrope of Song et al.(1997) is comparable with the calculated reactive azeotrope of this work if distance to experimental reactive azeotrope is used as criteria of comparison $(\Delta \mathrm{x}, \Delta \mathrm{y}, \Delta \mathrm{T}$ of Table 8$)$. The good performance of the NRTL binary parameters used by Song et al.(1997) may suggest that their procedure of adjusting nonreactive azeotropes to obtain binary parameters is good for predicting multicomponent reactive azeotropes. The similar approach of using binary azeotropes to estimate binary parameters in activity coefficient models to predict ternary azeotrope in nonreactive mixtures has been presented in the literature (Mandagarán and Campanella, 1999).

An additional calculation was to draw the distillation line map, which is presented in Figure 9. Compositions in the Figure are the transformed coordinates of Ung and Doherty (1995). The diagram displays two binary azeotropes, which are the nonreactive azeotropes between isopropanol and isopropyl acetate, and isopropanol and water. The diagram also shows the four-component minimumboiling reactive azeotrope. One set of distillation lines starts at the acetic acid node and ends at the reactive azeotrope node. The other set of distillation lines starts at the isopropanol node and ends at the reactive azeotrope node. In the case of the quaternary reactive mixture of acetic acid-isopropanol-waterisopropyl acetate all the reactive distillation lines end at the reactive azeotrope. Distillation line diagram is a key concept to analyze reactive distillation feasibility (Bessling et al., 1997) and in this work was used to check reactive azeotrope calculation.

\section{CONCLUSIONS}

The vapor - liquid equilibrium quaternary reactive system acetic acid - isopropanol - water isopropyl acetate experimental data can be predicted using a NRTL model. The procedure to calculate the binary parameters and the chemical equilibrium constant is very different from others procedures developed in the literature. In this work binary parameters were obtained from binary data and the chemical equilibrium constant was obtained from the experimental reactive azeotrope. Compared with the other alternatives to correlate the experimental data, the NRTL model of this work calculate well reactive and nonreactive azeotropes and predict very well the quaternary reactive data of Teodorescu et al. (2001) and of Lee and Kuo (1996). The model can be also used for prediction of vapor-liquid equilibrium of the binary and ternary systems. Calculations of ternary liquid - liquid equilibrium and vapor - liquid - liquid equilibrium agree well with the experimental values.

\section{ACKNOWLEDGMENT}

The authors are thankful for the financial aid received from CONICET and Universidad Nacional del Litoral.

\section{NOMENCLATURE}

$f_{i} \quad$ fugacity of component $i$

$\mathrm{G}$ molar Gibbs energy

$\mathrm{K}$ equilibrium constant of reaction

$\mathrm{P}$ total pressure

$\mathrm{R} \quad$ Universal gas constant

$\mathrm{T}$ temperature

$\mathrm{x}_{\mathrm{i}} \quad$ liquid phase mole fraction of component $\mathrm{i}$

$\mathrm{X}_{\mathrm{i}} \quad$ transform liquid phase coordinates of Ung and Doherty of component i (eq. 6)

$y_{i} \quad$ vapor phase mole fraction of component $\mathrm{i}$

$\mathrm{Y}_{\mathrm{i}} \quad$ transform vapor phase coordinates of Ung and Doherty of component i (eq. 7)

\section{Greek Letters}

$\Phi_{\mathrm{i}} \quad$ fugacity coefficient of component i

$\gamma_{i} \quad$ activity coefficient of component $i$

$v_{i} \quad$ stecheometric coefficient of component $i$

\section{Subscripts}

i component

$\mathrm{k} \quad$ reference component

$\mathrm{T}$ total

\section{Superscripts}

$0 \quad$ standard state

L liquid phase

$\mathrm{v} \quad$ vapor phase 


\section{REFERENCES}

Abrams, D. and Prausnitz, J., Statistical Thermodynamics of Liquid Mixtures: A New Expression for the Excess Gibbs Energy of Partly or Completely Miscible Systems. AIChE J., 21, 116 (1975).

Amer Amezaga, S. and Fernandez Biarge, J., LiquidVapor Equilibrium in Binary Systems formed by Acetic acid and Propyl, Isopropyl, Isobutyl, secbutyl and tert-butyl alcohols at $760 \mathrm{~mm}$. An. Quim., 69, 587 (1983).

Bessling, B., Schembecker, G. and Simmrock, K.H., Design of Processes with Reactive Distillation Line Diagrams. Ind. Eng. Chem. Res., 36, 3032 (1997).

Campanella, E.A. and Mandagaran, B.A., Phase Equilibria for Quaternary Mixtures in Esterification Reaction Systems. Latin American Applied Research, 33, 313 (2003).

Fredenslund, A., Gmehling, J. and Rasmussen, P., Vapor-Liquid Equilibria using UNIFAC: A Group Contribution Method. Elsevier, Amsterdam (1977).

Fredenslund, A., Jones, R. and Prausnitz, J., Group Contribution Estimations of Activity Coefficients in Non-Ideal Liquid Mixtures. AIChE J., 21, 1086 (1975).

Gmehling, J., Menke, J., Krafczyk, J. and Fischer, K., Azeotropic Data. VCH-Verlagsgesellschaft, Weinheim, Germany (1994).

Gmehling, J., Onken, U. and Arlt, W., Vapor-Liquid Equilibrium Data Collection. In DECHEMA Chemistry Data Series. DECHEMA, Frankfurt, Germany (1977-1979).

Hayden, J. and O'Connell, J., A Generalized Method for Predicting Second Virial Coefficients. Ind. Eng. Chem. Process Des. Dev., 14, 209 (1975).

Hlavaty, K. and Linek, J., Liquid-Liquid Equilibria in Four Ternary Acetic Acid Organic SolventWater Systems at 24.6 C. Collect Czech. Chem. Commun., 38, 374 (1973).

Hong, G-B, Lee, M-J and Lin, H-M, Multiphase Coexistence for Mixtures Containing Water, 2Propanol, and Isopropyl Acetate, Ind. Eng. Chem. Res., 42, 937 (2003).

Kang, Y., Lee, Y. and Lee, W., Vapor-Liquid Equilibria with Chemical Reaction Equilibrium Systems Containing Acetic Acid, Ethyl Alcohol, Water and Ethyl Acetate. J. Chem. Eng. Jpn., 25, 649 (1992).

Lee, L. and Kuo, M., Phase and reaction equilibria of the acetic acid-isopropanol-isopropyl acetatewater system at $760 \mathrm{mmHg}$. Fluid Phase Equilibria, 123, 147 (1996).
Linek, J. and Wichterle, I., Liquid-vapor equilibrium in the ternary isopropyl acetate-water- acetic acid and isopropyl acetate-water-acrylic acid systems at 200 Torr. Collect Czech. Chem. Commun., 39, 3395 (1974).

Maier, R.W., Brennecke, J.F. and Stadtherr, M.A., Reliable computation of reactive azeotropes. Computers and Chemical Engineering, 24, 1851 (2000).

Mandagarán, B. and Campanella, E., Prediction of Ternary Azeotrope Concentration and Temperature. Información Tecnológica, 10, 103 (1999).

Marek, J. and Standart, G., Vapour-liquid equilibria in mixtures containing an associating substance. I. Equilibrium relationships for systems with an associating component. Collect. Czech. Chem. Commun., 19, 1074 (1954).

Miller, J.C. and Miller, J.N., Estadística para Química Analítica, Addison-Wesley Iberoamerican S.A. (1993).

Renon, H. and Prausnitz, J., Local Composition in Thermodynamic Excess Functions for Liquid Mixtures. AIChE J., 14, 135 (1968).

Sebastiani, E. and Lacquaniti, L., Acetic Acid-Water System Thermodynamical Correlation of VaporLiquid Equilibrium Data. Chem. Eng. Sci., 22, 1155 (1967).

Song, W., Huss, R., Doherty, M. and Malone, M., Discovery of a reactive azeotrope. Nature, 388 , 561 (1997).

Ung, S. and Doherty, M., Necessary and Sufficient Conditions for Reactive Azeotropes in Multireaction Mixtures. AIChE J., 41, 2383 (1995).

Sorensen, J. and Arlt, W., Liquid-Liquid Equilibrium Data Collection. In DECHEMA Chemistry Data Series. DECHEMA, Frankfurt, Germany. Vol. V, Part. 1, p. 294 (1979).

Teodorescu, M., Aim, K. and Wichterle, I., Isothermal Vapor-Liquid Equilibrium in the Quaternary Water + 2-Propanol + Acetic Acid + Isopropyl Acetate System with Chemical Reaction. J. Chem. Eng. Data, 46, 261 (2001).

Tochigi, K., Minami, S. and Kojima, K., Prediction of Vapor-Liquid Equilibria with Chemical Reaction by Analytical Solutions of Groups. J. Chem. Eng. Jpn., 10, 349 (1977).

Wilson, G., Vapor-Liquid Equilibrium. XI: A New Expression for the Excess Free Energy of Mixing. J. Amer. Chem. Soc., 86, 127 (1964).

Wilson, A. and Simons E., Vapor-Liquid Equilibria 2 Propanol-water System. Ind. Eng. Chem., 44, 2214 (1952). 